\title{
(2) OPEN ACCESS \\ Characterising variability and predictors of infant mortality in urban settings: findings from 286 Latin American cities
}

\author{
Ana F Ortigoza (D, ${ }^{1}$ José A Tapia Granados (DD, ${ }^{2}$ J Jaime Miranda (D), ${ }^{3}$ \\ Marcio Alazraqui, ${ }^{4}$ Diana Higuera, ${ }^{5}$ Georgina Villamonte, ${ }^{3}$

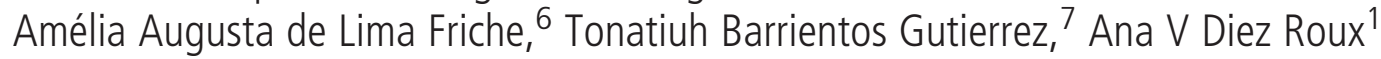

- Supplemental material is published online only. To view please visit the journal online (http://dx.doi.org/10.1136/ jech-2020-215137).

For numbered affiliations see end of article.

\section{Correspondence to}

Ana F Ortigoza, Urban Health

Collaborative, Drexel

University, 3600 Market

Street, Room 717E,

Philadelphia, PA 19104, USA; afo25@drexel.edu

Received 17 July 2020 Revised 23 September 2020 Accepted 25 September 2020 Published Online First 15 October 2020

\begin{abstract}
Background Urbanisation in Latin America (LA) is heterogeneous and could have varying implications for infant mortality (IM). Identifying city factors related to IM can help design policies that promote infant health in cities.

Methods We quantified variability in infant mortality rates (IMR) across cities and examined associations between urban characteristics and IMR in a crosssectional design. We estimated IMR for the period 2014-2016 using vital registration for 286 cities above 100000 people in eight countries. Using national censuses, we calculated population size, growth and three socioeconomic scores reflecting living conditions, service provision and population educational attainment. We included mass transit availability of bus rapid transit and subway. Using Poisson multilevel regression, we estimated the per cent difference in IMR for a one SD (1SD) difference in city-level predictors.
\end{abstract}

Results Of the 286 cities, 130 had $<250000$ inhabitants and 5 had $>5$ million. Overall IMR was 11.2 deaths/1000 live births. $57 \%$ of the total IMR variability across cities was within countries. Higher population growth, better living conditions, better service provision and mass transit availability were associated with $6.0 \%$ (95\% Cl -8.3 to $3.7 \%), 14.1 \%(95 \% \mathrm{Cl}-18.6$ to -9.2$)$ $11.4 \%(95 \% \mathrm{Cl}-16.1$ to -6.4$)$ and $6.6 \%(95 \% \mathrm{Cl}-9.2$ to -3.9 ) lower IMR, respectively. Greater population size was associated with higher IMR. No association was observed for population-level educational attainment in the overall sample.

Conclusion Improving living conditions, service provision and public transportation in cities may have a positive impact on reducing IMR in LA cities.

\section{BACKGROUND}

Infant mortality (IM) is often considered a marker of the degree of a country's social and economic development because infant wellness and survival are closely related to the conditions into which infants are born and in which they grow. ${ }^{1}$ In low- and middle-income countries, infant mortality rates (IMR) have dropped significantly over last three decades, mostly due to reductions in deaths caused by conditions preventable or treatable through sanitation, maternal and perinatal care, and immunisation coverage. ${ }^{2}$ By 2010, LA showed the lowest IMR among developing regions, although the rate of decline has experienced a slowdown compared to other regions since 2005. ${ }^{3}$ This stagnation in the decrease of mortality rates could result from the fact that once easily preventable causes of death are tackled, achieving further reductions requires addressing drivers of mortality related to social inequalities in the population.

LA is one of the most urbanised regions in the world. ${ }^{4}$ While cities have been seen as places of economic opportunities and better access to services such as education and healthcare, ${ }^{5}$ many aspects of life in cities can negatively affect infant and child health. The accelerated urban population growth that occurred over the last three decades resulted in rapid expansion of many cities with inadequate urban planning. ${ }^{6}$ Cities can have hazardous levels of air pollution, which has been linked to premature birth, and higher morbidity and mortality among infants. ${ }^{8} 9$ In addition, almost $20 \%$ of the population currently lives in poverty. ${ }^{6} 10$ This creates a particularly vulnerable environment for infants as a result not only of poorer access to care but also because of greater exposure to social and environmental conditions hazardous to health. ${ }^{10}$ This heterogeneity in urban environment observed within and across urban areas in LA challenges the idea of 'urban advantage', by which cities are believed to have lower maternal and IMR compared to rural areas. ${ }^{11}$

Social inequalities linked to child mortality have been extensively described at the national or subnational levels ${ }^{12}{ }^{13}$; however, analyses at the city level have been mostly restricted to a few big metropolitan areas. ${ }^{14} 15$ Examining how characteristics of cities affect mortality and health outcomes is important to identify actions and policies to improve infant health and promote health equity in the context of a rapidly urbanising world. We used data from a unique multinational urban health collaboration to quantify differences in IMR across a wide range of cities in LA and to examine how key features of cities are related to IMR.

\section{METHODS \\ Sample}

Data for this study are drawn from the SALURBAL project (SALud URBana en America Latina- Urban Health in Latin America), which includes all cities of 100000 or more inhabitants in 2010 in 11 countries for a total of 371 cities. Each city was defined geographically by administrative units (ie, municipios, comunas, partidos, 
delegaciones, cantones or corregimientos) that encompassed the urban extent of the city in 2010 using satellite imagery. ${ }^{16}$ For this study, we included cities for which vital statistics registries were available from 2014 to 2016 and presented good quality of death registry based on a separate analysis of adult mortality. ${ }^{17}$ We assumed that cities with good levels of registration for adult deaths (coverage of $90 \%$ or above) also have good coverage of deaths among infants. We included 286 cities in Argentina, Brazil, Chile, Colombia, Costa Rica, Mexico, Peru and Panama. Eleven cities (five cities in Nicaragua, three cities in Guatemala and El Salvador, respectively) were excluded due to lack of vital registration for the years of study. A total of 74 cities (9 cities in Brazil, 19 in Colombia, 31 in Mexico and 15 in Peru) were excluded because the estimated coverage of adult mortality was considered of low quality. Mean level of mortality coverage in all excluded cities was below $85 \%$ and excluded cities had poorer living conditions and lower provision of water connected to public network compared to cities included in this study (online supplemental material).

\section{Outcome}

IMR. We calculated IMR (deaths less than 1 year of age per 1000 live births) for the period 2014-2016. Deaths and live birth were retrieved based on deceased's and maternal place of residence, respectively. Three years were pooled to increase the stability of the estimates.

\section{Exposures}

We explored several characteristics of cities that we hypothesised would be related to IMR based on prior literature. ${ }^{6} 1013$

City population: we obtained population data from national censuses that provided estimates or projections for years 2010 and 2015. We investigated population size in 2010 as a continuous variable and categorised as (1) below a quarter million, (2) greater or equal to quarter million to less than half million, (3) greater or equal to half million to less than one million, (4) greater or equal to one million to less than five million, and (5) greater or equal to five million.

Annual population growth rate (APGR): this was calculated based on differences in population size between 2015 and 2010.

Urban social environment: we retrieved census indicators and harmonised them across countries for 12 socioeconomic (SE) variables describing education, housing, water, sanitation and employment. Using principal component analyses, we identified three components that incorporated seven variables. Variables related to employment (per cent of unemployed and per cent of labour force participation) and housing materials (per cent of houses with either durable walls or masonry walls) did not load onto any of the three components.

Each indicator was standardised to a mean of 0 and SD of 1 , and indicators that loaded onto each component were summed to create three SE scores. Each score may be related to IMR through different mechanisms:

- Score of living conditions (related to housing and poverty), including (1) per cent of households with piped water inside the dwelling; (2) per cent of households with overcrowding (more than three people per room, excluding kitchen and bathroom); and (3) per cent of population aged 15-17 years attending school, as a marker of social inclusion, since low school attendance among adolescents has been linked to poverty ${ }^{18}$ and exclusion from productive systems. ${ }^{19}$ We reverse coded the overcrowding indicator so that higher score values signify better living conditions.
- Score of service provision (related to public services that cities provide to dwellings), including (1) per cent of households with access to water from a municipal public or private water network, and (2) per cent of households with sewage system connected to a municipal public or private sewage network. Higher score values signify better service provision.

- Score of educational attainment (as a marker of SE context) including (1) per cent of population aged 25 years or above that has completed high school level or above, and (2) per cent of population aged 25 years or above that completed university level or above. This score characterises SE aspects of cities different from living conditions and service provision captured in the other two scores. ${ }^{20}$ Higher score values signify better educational achievement in the population.

Urban built environment: we created an indicator of mass transit availability based on the presence of subway and bus rapid transit (BRT) networks in the city. Mass transit availability was considered as present if the city had either subway or BRT network available, and absent when none of these options were present.

\section{Other variables}

Healthcare access: access to healthcare services for infants was proxied by the city coverage of first dose of triple viral vaccine (MMR1, measles-mumps-rubella vaccine) among the population of 1-year-olds. MMR1 presents a schedule that is similar across countries making it suitable for harmonisation. Data for the year 2016 were provided by WHO. ${ }^{21}$

National gross domestic product per capita (GDP per capita): we retrieved the national real GDP (output-based) per population for 2015 for each country from Penn World Tables ${ }^{22}$ and use the median value of the sample (US\$15 530.7) to categorise countries in two groups: above and below the median GDP per capita. We stratified on GDP because country economic conditions could modify the importance of the city-level factors, we studied for IM.

\section{Statistical analysis}

We described the distribution of city characteristics by categories of city population size. We examined the distribution of IMR and city-level predictors in the overall sample and by countries. Since IMR was approximately normally distributed in our sample, we decomposed the total variance in IMR across and within countries using a linear mixed model with a random intercept for each country and no covariates. We then estimated the association of city-level variables with IMR using a Poisson multilevel model. City-level predictors were first explored separately and then combined. To determine whether associations of city variables with IMR were independent of access to healthcare, we further adjusted for MMR1 coverage.

We explored effect modification by country GDP per capita by repeating analyses in countries with GDP per capita above and below the median value of the sample, and by testing for statistical interactions between GDP per capita and city-level predictors.

\section{RESULTS}

Selected characteristics of the cities are shown in table 1 . Of the 286 cities, about half (45.5\%) had less than a quarter million inhabitants and only five had over five million. Mean annual growth rates over the past 5 years were positive in all size categories and were slightly lower in the largest cities (4.2\% in cities of five million or more compared to around $7 \%$ per year for other cities). SE indicators did not differ substantially across city size. Cities over 
Table 1 Demographic and socioeconomic characteristics of cities by city population size ( $\mathrm{N}=286$ cities)

\begin{tabular}{|c|c|c|c|c|c|c|c|}
\hline & \multirow{2}{*}{$\begin{array}{l}\text { Total } \\
\mathrm{n} \text { (\% distribution) } \\
\text { or mean (SD) }\end{array}$} & \multicolumn{5}{|c|}{ City population size* } & \multirow[b]{2}{*}{$P$ value } \\
\hline & & $100000-250000$ & $250000-500000$ & 500 000-1 Million & 1-5 Million & $>5$ Million & \\
\hline Overall number of cities, $n$ (\%) & 286 & $130(45.5 \%)$ & $70(24.5 \%)$ & $47(16.4 \%)$ & $34(11.9 \%)$ & $5(1.7 \%)$ & \\
\hline \multicolumn{8}{|l|}{ Number of cities by country, $\mathrm{n}$ (col\%) } \\
\hline Argentina & $33(11.5 \%)$ & $15(11.5 \%)$ & $8(11.4 \%)$ & $5(10.6 \%)$ & $4(11.8 \%)$ & $1(20.0 \%)$ & \\
\hline Brazil & $143(50.4 \%)$ & $74(56.9 \%)$ & $31(44.3 \%)$ & $19(40.4 \%)$ & $17(50.0 \%)$ & $2(40.0 \%)$ & \\
\hline Chile & $21(7.3 \%)$ & $12(9.3 \%)$ & $6(8.5 \%)$ & $2(4.3 \%)$ & - & $1(20.0 \%)$ & \\
\hline Colombia & $16(5.6 \%)$ & $6(4.7 \%)$ & $5(7.0 \%)$ & $4(8.5 \%)$ & $1(2.9 \%)$ & - & \\
\hline Costa Rica & $1(0.3 \%)$ & - & - & - & $1(2.9 \%)$ & - & \\
\hline Mexico & $61(21.3 \%)$ & $19(14.6 \%)$ & $16(22.9 \%)$ & $15(31.9 \%)$ & $10(29.4 \%)$ & $1(20.0 \%)$ & \\
\hline Panama & $3(1.0 \%)$ & $2(1.6 \%)$ & - & - & $1(2.9 \%)$ & - & \\
\hline Peru & $8(2.8 \%)$ & $2(1.6 \%)$ & $4(5.6 \%)$ & $2(4.3 \%)$ & - & - & \\
\hline Population growth ratet, mean\% (SD) & $6.5(3.3)$ & $6.5(3.7)$ & $6.7(3.2)$ & $6.6(2.5)$ & $6.4(2.6)$ & $4.2(1.1)$ & 0.559 \\
\hline 1. Score of Living conditions, mean (SD) & $0.06(0.7)$ & $0.13(0.7)$ & $-0.02(0.7)$ & $-0.03(0.7)$ & $0.08(0.4)$ & $0.22(0.4)$ & 0.613 \\
\hline$\%$ of households with piped water in the dwelling & $89.9(11.4)$ & $91.1(11.1)$ & $87.5(13.3)$ & $88.7(11.8)$ & $91.7(7.2)$ & $92.6(7.2)$ & 0.227 \\
\hline$\%$ of households with overcrowding $\ddagger$ & $5.0(4.0)$ & $4.5(4.3)$ & $5.5(4.0)$ & $5.6(3.9)$ & $4.8(3.0)$ & $5.2(2.6)$ & 0.429 \\
\hline$\%$ of population $15-17$ attending school & $80.3(7.6)$ & $80.7(7.9)$ & $80.2(7.6)$ & $79.5(6.9)$ & $79.4(7.5)$ & $83.4(5.0)$ & 0.691 \\
\hline 2. Score of Service provision, mean (SD) & $-0.08(0.4)$ & $-0.1(0.6)$ & $-0.08(0.4)$ & $-0.03(0.4)$ & $-0.07(0.4)$ & $0.12(0.4)$ & 0.766 \\
\hline $\begin{array}{l}\% \text { of households with water connected to } \\
\text { municipal network }\end{array}$ & $90.8(10.6)$ & $90.3(10.9)$ & $90.1(11.9)$ & $91.7(9.0)$ & $91.89(8.9)$ & $92.1(9.1)$ & 0.822 \\
\hline $\begin{array}{l}\% \text { of households with sewage system connected } \\
\text { to municipal network }\end{array}$ & $70.0(25.2)$ & $68.9(26.8)$ & $70.5(24.3)$ & $72.3(24.3)$ & $68.2(22.9)$ & $83.7(16.2)$ & 0.681 \\
\hline $\begin{array}{l}\text { 3. Score of Population Educational attainment, } \\
\text { mean (SD) }\end{array}$ & $-0.22(0.3)$ & $-0.35(0.3)$ & $-0.19(0.3)$ & $-0.04(0.3)$ & $-0.004(0.3)$ & $-0.03(0.2)$ & $<0.0001$ \\
\hline $\begin{array}{l}\% \text { Population } 25+\text { with complete high school or } \\
\text { above }\end{array}$ & $38.8(7.7)$ & $36.4(7.4)$ & $39.7(8.1)$ & $41.5(6.9)$ & $41.6(6.8)$ & $43.5(3.7)$ & $<0.0001$ \\
\hline $\begin{array}{l}\% \text { Population } 25+\text { with complete university level } \\
\text { or more }\end{array}$ & $12.2(4.2)$ & $10.7(3.8)$ & $12.2(4.1)$ & $14.3(4.0)$ & $14.9(3.4)$ & $13.6(3.9)$ & $<0.0001$ \\
\hline 4. Availability of mass transit, $n$ (col\%) & $41(14.3 \%)$ & - & $3(4.2 \%)$ & $13(27.7 \%)$ & $20(58.8 \%)$ & $5(100 \%)$ & $<0.0001$ \\
\hline Bus rapid transit & $40(14.0 \%)$ & - & $3(4.2 \%)$ & $12(25.5 \%)$ & $20(58.8 \%)$ & $5(100 \%)$ & $<0.0001$ \\
\hline Subway & $16(5.6 \%)$ & - & - & $2(4.3 \%)$ & $9(26.5 \%)$ & $5(100 \%)$ & $<0.0001$ \\
\hline MMR1 coverage, mean \% (SD) & $91.3(13.8)$ & $91.1(13.2)$ & $90.2(15.3)$ & $93.1(12.2)$ & $92.0(14.9)$ & $91.6(9.24)$ & 0.855 \\
\hline Overall infant mortality rate $\eta_{\text {, mean }}(\mathrm{SD})$ & $11.2(2.8)$ & $11.1(2.9)$ & $11.4(2.8)$ & $11.1(2.6)$ & $11.4(2.3)$ & $10.8(2.5)$ & 0.877 \\
\hline Argentina & $10.0(2.2)$ & $9.5(1.9)$ & $11.3(3.0)$ & $9.4(1.7)$ & $9.5(1.7)$ & $10.0()$. & 0.2976 \\
\hline Brazil & $11.9(2.4)$ & $11.7(2.4)$ & $11.9(2.1)$ & $11.9(3.1)$ & $12.4(2.3)$ & $12.1(1.2)$ & 0.8537 \\
\hline Chile & $7.4(0.9)$ & $7.6(1.1)$ & $7.2(0.6)$ & $6.5(0.3)$ & - & $6.8()$. & 0.3523 \\
\hline Colombia & $10.8(2.8)$ & $9.8(2.3)$ & $12.9(3.0)$ & $10.3(2.0)$ & $7.9()$. & - & 0.1735 \\
\hline Costa Rica & 7.5(.) & - & - & - & $7.5()$. & - & - \\
\hline Mexico & $11.8(2.4)$ & $12.7(3.2)$ & $11.0(1.5)$ & $11.6(1.87)$ & $11.4(1.9)$ & $13.0()$. & 0.3445 \\
\hline Panama & $13.1(2.2)$ & $14.2(1.7)$ & & - & $11.0()$. & - & 0.3573 \\
\hline Peru & $11.2(4.7)$ & $7.04(3.0)$ & $13.5(5.6)$ & $11.0(1.21)$ & - & - & 0.3414 \\
\hline
\end{tabular}

${ }^{*}$ City population size is defined by the population in 2010.

tPopulation growth for the period 2010-2015.

$\ddagger$ Overcrowding is defined as more than three people per room, excluding kitchen and bathroom in a household.

$\S$ Mass transit availability refers to the presence of either subway or bus rapid transit networks.

IInfant mortality rate=number of infant deaths per 1000 live births.

MMR1, measles-mumps-rubella vaccine.

one million tended to have higher proportions of households with piped water in the dwelling than cities with less than one million, but differences across city sizes were not statistically significant (table 1). Cities below a quarter million showed lower mean levels of education: $36.4 \%$ of the population with complete high-school or above, and $10.3 \%$ of population with complete university or above compared to about $42 \%$ and $14 \%$ in the rest of the cities, respectively. Cities below a quarter million did not have subways or BRT, and availability of mass transit was higher in larger cities: while only $25.5 \%$ and $4.3 \%$ of the cities between half to one million residents had BRT and subway systems, respectively, all cities with more than five million residents had both BRT and subways. The mean level of vaccine coverage in the sample was $91.3 \%$ and did not differ by city size. Mean IMR was 11.2 deaths per 1000 live births and only cities over five million had IMR below the mean. Cities in Argentina, Chile, Colombia and Costa Rica showed mean IMR below the overall mean for the full sample (table 1).

Figure 1 shows distribution of IMR for cities within countries. Although median IMR differed across countries, the greatest 
Infant Mortality in 286 Latin American Cities (2014-2016)

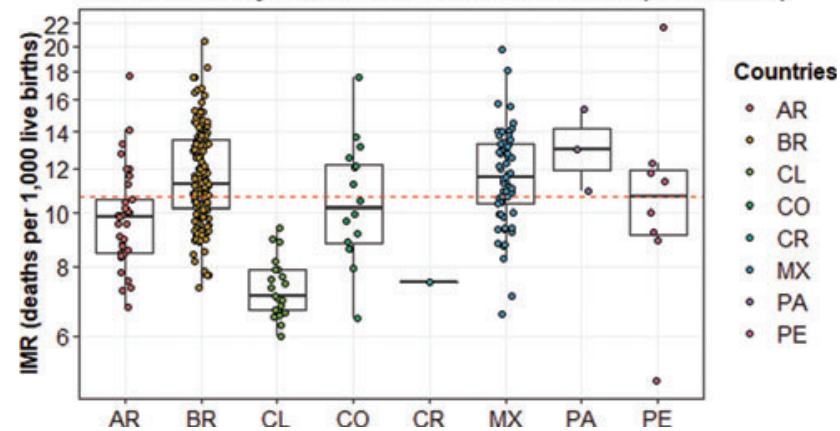

Figure 1 Distribution of infant mortality rate (IMR) in cities by country, 2014-2016 ( $n=286$ cities). Each dot represents a city-estimate of IMR, and boxplots show the country distribution of IMR. Dashed line describes the median IMR of the overall sample (11 deaths per 1000 live births).

$A R$, Argentina; BR, Brazil, CL, Chile; CO, Colombia; CR, Costa Rica; MX, Mexico; PA, Panama; PE, Peru.

heterogeneity is observed across cities within countries. The intraclass correlation was 0.43 implying that $57 \%$ of the total variability in city-level IMR was within countries.

Table 2 shows estimated per cent differences in IMR associated with a 1SD higher population size, APGR, SE scores, mass transit availability and 1\% higher MMR1 coverage. In the models with each exposure separately, the three SE scores showed negative associations with IMR. When all exposures were adjusted for each other, higher city growth, better living conditions, better service provision and availability of mass transit were associated with lower IMR: 1SD higher APGR was associated with 6.0\% lower IMR (95\% CI -8.3 to $-3.7 \%)$, 1SD higher score of living condition with $14.1 \%$ lower IMR (95\% CI -18.6 to -9.2$)$, 1SD higher score of service provision with $11.4 \%$ lower IMR (95\% CI -16.1 to -6.4 ), and the presence of mass transit with 6.6\% lower IMR (95\% CI -9.2 to -3.9$)$. No association was observed for population-level educational attainment in the multivariable model. One SD higher population size was associated with $0.7 \%$ higher IMR (95\% CI 0.1 to 1.4 ). These results did not change substantially after accounting for MMR1 coverage.

When countries were grouped by GDP per capita (table 3), better living conditions and mass transit availability were similarly associated with lower IMR at high and low GDP levels, but better service provision was associated with lower IMR only for countries of lower GDP ( $\mathrm{p}$ value for interaction 0.0001). Higher population growth was also similarly associated with lower IMR at higher and lower levels of GDP, but greater population size appeared to be more strongly associated with higher IMR in countries with higher GDP ( $p$ value for interaction 0.002). Although a statistically significant interaction with country GDP was also observed for education, CIs were very wide in both GDP strata.

To explore the influence of outliers, we carried out sensitivity analysis excluding cities above the 99th or below the 1st percentile of IM and found similar results. The exclusion of Peru (which has been reported to have significant undercounting of infant deaths in some studies ${ }^{23}$ ) also yielded similar results.

\section{DISCUSSION}

This study showed substantial heterogeneity in IMR across LA cities. Although countries differed in IMR, most of the variability in city-level IMR (almost 57\%) was within countries. Higher population growth rate, better living conditions and services provision and availability of mass transit were associated with lower IMR, independently of access to healthcare. Greater population size was associated with higher IMR. GDP per capita modified these associations, such that services provision was associated with lower IMR only in countries with GDP per capita below the median.

The large heterogeneity in IMR observed across cities (even within the same country) highlights the importance of examining city-level factors as predictors of IMR. In our study, city-level measures of living conditions (reflecting housing, crowding and schooling in adolescents) and services provision (water and sanitation) were independently associated with lower IMR. Quality housing as well as access to water and sanitation services are known to reduce the transmission of respiratory and enteric diseases, ${ }^{24}$ which remain the main causes of death among

Table 2 Estimated per cent differences in IMR associated with city-level predictors $(n=286)$

\begin{tabular}{|c|c|c|c|c|c|c|}
\hline & \multicolumn{2}{|c|}{$\underline{\text { Single-exposure models }}$} & \multicolumn{2}{|c|}{ Multivariable $\ddagger$} & \multicolumn{2}{|c|}{ Adjusted for healthcare§§ } \\
\hline & $\%$ Difference & $95 \% \mathrm{Cl}$ & $\%$ Difference & $95 \% \mathrm{Cl}$ & $\%$ Difference & $95 \% \mathrm{Cl}$ \\
\hline Population size* & -0.1 & -0.9 to 0.8 & 0.7 & 0.1 to 1.4 & 0.8 & 0.2 to 1.3 \\
\hline Population growth rate & -3.6 & -6.8 to -0.3 & -6.0 & -8.3 to -3.7 & -6.0 & -8.3 to -3.6 \\
\hline Living conditions score $\ddagger$ & -18.4 & -26.7 to -9.2 & -14.1 & -18.6 to -9.2 & -14.1 & -18.8 to -9.2 \\
\hline Services provision score§ & -13.2 & -17.1 to -9.2 & -11.4 & -16.1 to -6.4 & -11.0 & -15.5 to -6.2 \\
\hline Population educational attainment scoreq & -13.7 & -21.7 to -4.8 & 1.4 & -1.2 to 4.1 & 0.9 & -1.7 to 3.6 \\
\hline Availability of mass transit** & -3.9 & -11.2 to 4.0 & -6.6 & -9.2 to -3.9 & -6.7 & -9.2 to -4.2 \\
\hline MMR1 coverage†† & & & & & -0.1 & -0.2 to 0.04 \\
\hline
\end{tabular}

*Population size is defined as 1SD higher the population in 2010.

tPopulation growth rate is defined as 1SD higher annual difference in population size from 2010 to 2015

fLiving conditions score includes per cent of households with piped water in the dwelling, per cent of households with overcrowding ( $3+$ per room) in the house and per cent of population aged 15-17 years attending school;

§Services provision score includes per cent of households with water connected to municipal network and per cent of households with sewage system connected to municipal network.

IPopulation-level educational attainment score includes per cent of population aged 25 years or above with complete high school level or above, per cent of population aged 25 years or above with complete university level or above.

** Mass transit availability refers to the presence of either subway or bus rapid transit networks.

††MMR1 coverage represents the percentage of 1-year-old children, who received the first dose of MMR1 among overall population of 1-year-olds.

¥¥Multivariable model includes all city-level predictors except MMR1 coverage.

$\S \S$ Includes all variables in multivariable model and MMR1 coverage.

Estimates correspond to per cent differences in IMR for 1 SD higher SE scores, population size and growth, $1 \%$ higher MMR1 coverage and the availability of mass transit.

IMR, infant mortality rate; MMR1, first dose measles-mumps-rubella vaccine; SE, socioeconomic; 1SD, one SD. 
Table 3 Estimated percentage difference in IMR associated with city-level predictors stratified by country GDP per capita

\begin{tabular}{|c|c|c|c|c|c|}
\hline & \multicolumn{2}{|c|}{$\begin{array}{l}\text { Countries below median GDP } \neq \\
\mathrm{n}=168 \text { cities }\end{array}$} & \multicolumn{2}{|c|}{$\begin{array}{l}\text { Countries above median GDP§§ } \\
\mathrm{n}=118 \text { cities }\end{array}$} & $\begin{array}{l}\text { Test for interaction } 19 \\
\mathrm{P} \text { value }\end{array}$ \\
\hline Population size* & 0.4 & -0.2 to 0.9 & 1.2 & -0.5 to 3.0 & 0.0017 \\
\hline Living conditions scoreł & -18.0 & -26.7 to -8.2 & -16.3 & -19.0 to -13.5 & 0.0469 \\
\hline Services provision score§ & -11.7 & -14.4 to -8.8 & 2.7 & -0.7 to 6.3 & $<0.0001$ \\
\hline MMR1 coveraget† & -0.2 & -0.2 to -0.1 & 0.01 & -0.4 to 0.5 & 0.2766 \\
\hline
\end{tabular}

*Population size is defined as 1SD higher the population in 2010.

tPopulation growth rate is defined as 1SD higher annual difference in population size from 2010 to 2015.

fLiving conditions score includes per cent of households with piped water in the dwelling, per cent of households with overcrowding ( $3+$ per room) in the house and per cent of population aged 15-17 years attending school.

$\S$ Services provision score includes per cent of households with water connected to municipal network and per cent of households with sewage system connected to municipal network.

१Population-level educational attainment score of 3 includes per cent of population aged 25 years or above with complete high school level or above and per cent of population aged 25 years or above with complete university level or above.

${ }^{* *}$ Mass transit availability refers to the presence of either subway or bus rapid transit networks;

†TMMR1 coverage represents the percentage of 1-year-old children who received the first dose of measles-mumps-rubella vaccine among overall population of 1 -year-olds.

$\neq \neq$ Countries with GDP/capita below the median (US\$15 530): Brazil, Colombia, Costa Rica and Peru.

$\S \S$ Countries with GDP/capita above the median (US\$15 530): Argentina, Chile, Mexico and Panama.

१ๆEach interaction was tested separately along with the full model. GDP was coded as GDP=0 for countries with GDP/capita below the median, and GDP=1 for countries above the median.

Estimates correspond to per cent differences in IMR for 1SD higher SE scores, population size and growth, 1\% higher MMR1 coverage and the availability of mass transit.

GDP, gross domestic product; IMR, infant mortality rate; MMR1, measles-mumps-rubella vaccine; SE, socioeconomic; $1 S D$, one SD.

infants. ${ }^{25}$ Prior work has shown that urban slum prevalence is related to IMR across countries, ${ }^{26} 27$ but these studies did not identify the features of slums that may be most important and ignore heterogeneities across cities. We show that specific living conditions and service provision at the city level are related to IMR in cities, highlighting the potential role of city-level policies affecting these factors in reducing IMR in urban areas.

We also found that higher population growth was associated with lower IMR while greater population size was related to higher IMR, after accounting for other city predictors. Further analyses are needed to examine how the population dynamics of cities may affect IMR. Population growth could reflect migration and/or natality rates. Decreased fertility and natality associated with improved status of women have been linked to lower IMR. ${ }^{28}$ Increased population growth at the expense of migration from rural areas may reflect the influx of disadvantaged populations and may create demands that cities are unable to face resulting in higher IMR. ${ }^{29}$ However, we found that greater growth was associated with lower IMR suggesting that growth may be proxying other unmeasured factors related to lower IMR.

A novel aspect of our study was the investigation of public transportation, which has been hypothesised to impact health. ${ }^{30}$ We found that availability of BRTs and subways was associated with lower IMR independently of city population size and other city-level predictors. Availability of timely, rapid and extensive public transportation network may be key to reduce inequalities in access to healthcare related to IMR, as well as in access to employment opportunities and consequently better SE position for dwellers living in impoverished city areas. To our knowledge, this is the first study exploring the relationship between city transport and IMR. ${ }^{30}$ Given limitations in the information, we used to characterise public transportation these preliminary findings deserve further investigation.

Country economic development appeared to modify some of the associations between city-predictors and IMR. We found that better service provision was only associated with lower IMR in cities of countries with GDP per capita below the median. This may be related to greater variability in these predictors across cities in countries with lower GDP income or to the fact they are relevant predictors in these contexts because of the causes of death driving IMR. ${ }^{2}$

Our study is unique and unprecedented in that we have compiled and harmonised data on urban environment, and IMR across nearly 300 cities in LA. We were able to describe heterogeneity in IMR across cities and study how a range of city-level factors are related to IMR. Although many studies have focused on IMR in urban areas, to our knowledge, this is the first investigation examining the influence of city social and built environments on IMR across multiple cities. Although several previous studies have documented associations of social and economic factors with IMR at the country level, ${ }^{31} 32$ few if any studies have examined these factors at the level of cities. The study of city-level factors is especially relevant to the development of local interventions. A growing body of work has documented how local interventions in cities can improve infant health. ${ }^{33}$ For example, housing improvements and water and sanitation provision, ${ }^{34} 35$ or more comprehensive urban redevelopment interventions ${ }^{36}$ have been linked to reduction in respiratory and enteric infections ${ }^{34} 35$ as well as in $\mathrm{IM}^{36}$ in urban slums in LA.

Because of the number of cities studied, some of the measures available had limitations. Measures of public transportation were limited to subways and BRTs. These have advantages to traditional buses, but they do not fully capture transit availability. We did not include other potentially relevant physical environment features such as air pollution or density of green areas. The characterisation of healthcare access for infants was restricted to coverage of MMR1, a single-dose vaccine that tends to be more equally distributed in the population than interventions requiring specialised personnel or complex technology. ${ }^{37}$ This measure clearly has important limitations and does not adequately capture the complexity of healthcare access. A better representation of healthcare access may require the combination of several indicators related to family planning, antenatal care, multiple vaccine coverages and access to treatment during disease episodes like diarrhoea or pneumonia. ${ }^{37}$ Lastly, our city-level 
analyses, although informative, ignore heterogeneity across neighbourhoods within cities.

Finally, we restricted our study to cities with good quality of mortality registries based on adult mortality estimations with the purpose of generating unbiased estimates of IM. However, it is possible that registration of infant deaths and live births could be conditioned by other determinants of under-registration different from the ones related to adult mortality. There is evidence that undercounting of child deaths may be especially problematic in some areas of Peru ${ }^{23}$ but sensitivity analyses excluding Peru resulted in similar findings. If more under-registration of infant deaths is associated with lower SE conditions, the associations we report may be underestimates of true associations. Future studies involving IM need to address under-registration through specific approaches that estimate IMR, like indirect demographic methods or statistical methods designed for small-area estimations.

\section{CONCLUSION}

In an increasingly urbanised world, it is critical to identify which urban policies are necessary to improve population health. Our city-level analyses show that features of urban social and physical environments are related to important differences in IMR across cities. Prioritisation of urban policies and interventions related to improving living conditions, sanitary services and public transportation availability may be necessary to have positive and sustained impacts on infant survival in urban areas.

\section{What is already known on this subject}

- Although many studies have described differences in infant mortality across countries or regions, little research has explored heterogeneity across cities within countries. This heterogeneity may be especially important in nations where rapid urbanisation has been heterogeneous. Identifying which aspects of the urban environment contribute to differences in infant mortality is important to inform policies and programmes to improve infant health.

\section{What this study adds}

- We found that in Latin America, although infant mortality rates (IMR) differ across countries, large heterogeneity is observed across cities within countries. Higher IMR were observed in cities with higher proportions of residents experiencing social exclusion, inadequate housing conditions and insufficient municipal provision of sanitary services. Availability of mass transit in cities was associated with lower IMR.

- Achieving further reductions in infant mortality in Latin America will require focusing on reducing social inequities in urban populations and prioritising interventions related to improving living conditions, sanitary services and public transportation.

\footnotetext{
Author affiliations

${ }^{1}$ Urban Health Collaborative, Drexel University, Philadelphia, Pennsylvania, USA ${ }^{2}$ History and Political Science, Drexel University, Philadelphia, Pennsylvania, USA ${ }^{3}$ CRONICAS Centre of Excellence in Chronic Diseases, Universidad Peruana Cayetano Heredia, Lima, Peru

${ }^{4}$ Instituto de Salud Colectiva, Universidad Nacional de Lanus, Lanus, Argentina

${ }^{5}$ Escuela de Medicina, Universidad de Los Andes, Bogota, Colombia
}

${ }^{6}$ School of Medicine, Universidade Federal de Minas Gerais Faculdade de Medicina, Belo Horizonte, Brazil

${ }^{7}$ Instituto Nacional de Salud Publica, Mexico DF, Mexico

\section{Twitter Ana F Ortigoza @AnaOrtigoza14.}

Acknowledgements We thank Usama Bilal, Lance Ballester, Kari Moore, Gina Lovasi and Yvonne Michael for their support in the harmonisation and creation of the mortality data, and in the overview of the paper design. The authors acknowledge the contribution of all SALURBAL project team members. For more information on SALURBAL and to see a full list of investigators, see https://drexel.edu/lac/salurbal/team/.

Contributors AFO and AVDR conceived the study. AFO did the statistical analyses. AFO and AVDR drafted the first version of the manuscript. MA, DH, GV, AAdLF and TBG participated in or supported data collection. JTG and JJM participated in the edition of the manuscript providing critical inputs. All authors participated in the interpretation of the results and approved the final version of the manuscript.

Funding This work was supported by the Wellcome Trust initiative 'Our Planet, Our Health' (grant 205177/Z/16/Z). The study funder had no role in study design, data collection, data analysis, data interpretation or writing of this study. The corresponding author had full access to all the data in the study and had final responsibility for the decision to submit for publication.

Competing interests None declared.

Patient consent for publication Not required.

Provenance and peer review Not commissioned; externally peer reviewed.

Data availability statement Data are available upon reasonable request.

Supplemental material This content has been supplied by the author(s). It has not been vetted by BMJ Publishing Group Limited (BMJ) and may not have been peerreviewed. Any opinions or recommendations discussed are solely those of the author(s) and are not endorsed by BMJ. BMJ disclaims all liability and responsibility arising from any reliance placed on the content. Where the content includes any translated material, BMJ does not warrant the accuracy and reliability of the translations (including but not limited to local regulations, clinical guidelines, terminology, drug names and drug dosages), and is not responsible for any error and/ or omissions arising from translation and adaptation or otherwise.

Open access This is an open access article distributed in accordance with the Creative Commons Attribution 4.0 Unported (CC BY 4.0) license, which permits others to copy, redistribute, remix, transform and build upon this work for any purpose, provided the original work is properly cited, a link to the licence is given, and indication of whether changes were made. See: https://creativecommons.org/licenses/ by $/ 4.0 /$.

\section{ORCID iDs}

Ana F Ortigoza http://orcid.org/0000-0001-8100-422X

José A Tapia Granados http://orcid.org/0000-0003-4101-1024

J Jaime Miranda http://orcid.org/0000-0002-4738-5468

\section{REFERENCES}

1 PAHO. La mortalidad de la niñez en las Américas. Tendencias y diferenciales. Análisis de casos. Panamerican Health Organization, 1991.

2 UNICEF. Child survival: a promise renewed. Key Findings. September 2015.

3 CEPAL. Goal 4: reducing child mortality Charts Available https://www.cepal.org/sites/ default/files/static/files/reporte_odm_4.pdf (accessed 31 Oct 2017)

4 World Bank development indicators. 2015 Available http://databank.worldbank.org/ data/reports.aspx? source=2\&Topic=16 (accessed 31 Oct 2017)

5 Glaeser E. Triumph of the city: how our greatest invention makes us richer, smarter, greener, healthier and happier. New York: MacMillan, 2011.

6 Jaitman L. Urban infrastructure in Latin America and the Caribbean: public policy priorities. Latin Am Econ Rev 2015;24:1.

7 UN-Habitat. The sustainable development goals report 2016. UN Habitat, 2016.

8 Gouveia N, Bremner N, Novaes HMD. Association between ambient air pollution and birth weight in São Paulo. Brazil Epidemiol Community Health 2004;58:8.

9 Heft-Neal S, Burney J, Bendavid E, et al. Robust relationship between air quality and infant mortality in Africa. Nature 2018;559:254-8.

10 Mahabir R, Crooks A, Croitoru A, et al. The study of slums as social and physical constructs: challenges and emerging research opportunities. Reg Studies Reg Sci 2016:3:399-419.

11 Sastry N. Trends in socioeconomic inequalities in mortality in developing countries: the case of child survival in Sao Paulo, Brazil. Demography 2004;41:22.

12 Biggs B, King L, Basu S, et al. Is wealthier always healthier? The impact of national income level, inequality, and poverty on public health in Latin America. Soc Sci Med 2010;71:266-73. 
13 Victora CG, Vaughan JP, Barros FC, et al. Explaining trends in inequities: evidence from Brazilian child health studies. Lancet 2000;356:1093-8.

14 Kimani-Murage EW, Fotso JC, Egondi T, et al. Trends in childhood mortality in Kenya: the urban advantage has seemingly been wiped out. Health Place 2014;29:95-103.

15 Quentin W, Abosede 0, Aka J, et al. Inequalities in child mortality in ten major African cities. BMC Med 2014;12:95.

16 Quistberg DA, Diez Roux AV, Bilal U, et al. Building a data platform for cross-country urban health studies: the SALURBAL study. J Urban Health 2019;96:311-37.

17 Bilal U, Alazraqui M, Caiaffa WT, et al. Inequalities in life expectancy in six large Latin American cities from the SALURBAL study: an ecological analysis. Lancet Planetary Health 2019;3:e503-e10.

18 Bodenhorn H. Urban poverty, school attendance, and adolescent labor force attachment: some historical evidence. Cambridge, MA: National Bureau of Economic Research, 2006

19 Cardenas M, de Hoyos M, Szekely M. Out-of-school and out-of-work youth in Latin America: a persistent problem in a decade of prosperity. Economia 16:37.

20 Howe LD, Galobardes B, Matijasevich A, et al. Measuring socio-economic position for epidemiological studies in low- and middle-income countries: a methods of measurement in epidemiology paper. Int J Epidemiol 2012;41:871-86.

21 WHO. Subnational Immunization coverage data Available https://www.who.int/immu nization/monitoring_surveillance/data/subnational/en/2019 (accessed 7 Jan 2019)

22 Feenstra RC, Inklaar R, Timmer M. The next generation of the Penn world table. Am Econ Rev. 2015;105:3150-82.

23 Vargas-Machuca J, Tavera Salazar M, Carrasco Gamarra M. Mortalidad Neonatal en el Perú y sus departamentos 2011-2012. Ministerios de Salud Peru, Lima: 2013.

24 MacMichael A. The urban environment and health in a world of increasing globalization: issues for developing countries. Bull World Health Organ 2000;78:10.

25 Liu L, Oza S, Hogan D, et al. Global, regional, and national causes of child mortality in 2000-13, with projections to inform post-2015 priorities: an updated systematic analysis. Lancet 2015;385:430-40.
26 Jorgenson A, Rice J, Clark B. Assessing the temporal and regional differences in the relationships between infant and child mortality and urban slum prevalence in less developed countries, 1990-2005. Urban Studies 2012;49:3495-512.

27 Rice J, Rice JS. The concentration of disadvantage and the rise of an urban penalty: urban slum prevalence and the social production of health inequalities in the developing countries. Int J Health Serv 2009;39:749-70.

28 Gasparini L, Marchionni L. Bridging gender gaps? The rise and deceleration of female labor force participation in Latin America: an overview. Documento de Trabajo Nro 185. Centro de Estudios Distributivos, Laborales y Sociales Maestría en Economía (CEDLAS) Facultad de Ciencias Económicas, Universidad de la Plata, 2015.

29 Fay M. The urban poor in Latin America. Washington, DC: The World Bank, 2005.

30 Lee J, Miller HJ. Measuring the impacts of new public transit services on space-time accessibility: an analysis of transit system redesign and new bus rapid transit in Columbus, Ohio, USA. App/ Geogr 2018;93:47-63.

31 Ferre JC. Economic inequalities in Latin America at the base of adverse health indicators. Int J Health Serv 2016;46:501-22.

32 Jorgenson AK, Burns TJ. Globalization, the environment, and infant mortality: a cross-national study. Humboldt J Soc Relat 2004;28:47

33 Henson RM, Ortigoza A, Martinez-Folgar K, et al. Evaluating the health effects of place-based slum upgrading physical environment interventions: a systematic review (2012-2018). Soc Sci Med 2020;261:113102.

34 Galiani S, Gertler PJ, Undurraga R, et al. Shelter from the storm: upgrading housing infrastructure in Latin American slums. J Urban Econ 2017;98:187-213.

35 Galiani S, González-Rozada M, Schargrodsky E. Water expansions in Shantytowns: health and savings. New York: Inter-American Development Bank, 2007.

36 Soares F, Soares Y. The socio-economic impact of Favela-Bairro: what do the data say? Washington, DC: Office of Evaluation and Oversight (OVE), 2005.

37 Barros AJ, Victora CG. Measuring coverage in MNCH: determining and interpreting inequalities in coverage of maternal, newborn, and child health interventions. PLoS Med 2013;10:e1001390. 